\title{
Treatment Options in Colorectal Liver Metastases: Hepatic Arterial Infusion
}

\author{
Alice Zervoudakis Taryn Boucher Nancy E. Kemeny \\ Department of Medicine, Gastrointestinal Oncology Service, Memorial Sloan Kettering Cancer Center, New York, NY, USA
}

\section{Keywords}

Hepatic arterial infusion, HAI - Colorectal liver metastases . Survival · Progression-free survival

\section{Summary}

Background: The liver is the most common site for metastases from colorectal cancer (CRC) with the majority of these patients having unresectable disease. Methods: This is a retrospective review of studies using hepatic arterial infusion (HAl) therapy to treat liver metastasis from CRC. A PubMed search of randomized controlled trials and retrospective studies from 2006 to present was conducted using the search terms 'hepatic arterial infusion (HAl) therapy', 'colorectal cancer', and 'treatment of liver metastases'. Results: The first randomized studies comparing HAl to systemic therapy with 5-fluorouracil/leucovorin produced significantly higher response rates of 41 versus $14 \%$. Systemic therapy has improved with the addition of irinotecan and oxaliplatin; however, the responses with $\mathrm{HAl}$ and these modern agents have also increased, with responses as high as $80 \%$. For patients with wild-type KRAS, HAl and systemic therapy produced a median survival of 68 months. In patients with refractory disease, response rates are in the $30 \%$ range with a median survival of 20 months. Adjuvant HAl after liver resection has shown an increase of hepatic disease-free survival and overall disease-free survival when compared to systemic therapy alone in three of four randomized trials. A recent update of the adjuvant trials after liver resection at Memorial Sloan Kettering Cancer Center has shown a 5 -year survival of $78 \%$. Conclusion: HAl therapy has a role in treating hepatic metastases from CRC in both the resectable and unresectable setting.

(C) 2017 S. Karger GmbH, Freiburg

\section{Introduction}

Colorectal cancer (CRC) is the third most common cancer worldwide, with approximately 1.4 million people diagnosed and almost 700,000 deaths in 2012 [1]. In the USA, CRC is the third leading cause of cancer death in both men and women, with an estimated 49,190 deaths to occur in 2016 [2].

The liver is the most common site for metastases, with approximately $60 \%$ of patients developing liver metastases throughout the course of their disease, which is a major cause of mortality [3]. Unfortunately, approximately $85 \%$ of patients will harbor unresectable disease in which the 5-year survival is typically $6-10 \%[4,5]$. Therefore, in these patients, treatment with systemic or liver-directed chemotherapy through hepatic arterial infusion (HAI) can be used to downsize the disease in the liver with the goal of conversion to resection [6-8].

For patients who are able to undergo surgical resection of liver metastases with or without adjuvant chemotherapy, an increased survival can be obtained. In recent decades, the 5-year survival for patients in the adjuvant setting has increased from 25-39\% [9] to $40-50 \%$ [10]. The improvement in survival is attributed to several factors including newer systemic chemotherapy agents such as oxaliplatin [11] and irinotecan [12], effective combination chemotherapy regimens such as FOLFIRI and FOLFOX [13], and molecular targeted agents against the vascular endothelial growth factor [14] and epidermal growth factor receptor $[15,16]$. Other factors that may improve survival include more effective surgical techniques $[17,18]$ and interventional radiology procedures [19].

Since the liver is the most common site of metastatic disease for patients with CRC, liver-directed therapies have been developed. This article will summarize the role of HAI chemotherapy in the treatment of metastatic CRC to the liver.

\section{KARGER}

(c) 2017 S. Karger GmbH, Freiburg

Fax +497614520714
Dr. Nancy E. Kemeny

Department of Medicine, Gastrointestinal Oncology Service Memorial Sloan Kettering Cancer Center

300 East $66^{\text {th }}$ Street, $10^{\text {th }}$ floor, New York, NY 10065 , USA kemenyn@ mskcc.org 


\section{Methods}

A PubMed search of randomized controlled trials and retrospective studies from 2006 to present was conducted using the search terms 'hepatic arterial infusion (HAI) therapy', 'colorectal cancer', and 'treatment of liver metastases'. Studies were excluded with less than 30 patients or which included other malignancies besides colon cancer.

\section{Rationale of Hepatic Arterial Infusion Chemotherapy}

There may be a stepwise pattern of metastatic spread in CRC with the cancer originating in the colon or rectum and spreading to the liver via the portal veins. The rationale for HAI chemotherapy is based on the dual blood supply in the liver, with liver metastases greater than $1 \mathrm{~cm}$ in diameter deriving blood supply from the hepatic artery, whereas normal hepatocytes are perfused by the portal vein [20]. HAI chemotherapy is administered in the gastroduodenal artery by a surgically implanted pump, a hepatic arterial port, or through a percutaneously placed catheter connected to an external pump.

Certain drugs with a high first-pass extraction can be delivered into the arterial circulation resulting in high drug concentrations in the liver with minimal systemic toxicity [21]. In choosing a drug agent for HAI, the aim should be i) to increase local concentration which increases therapeutic response and ii) to decrease systemic exposure and toxicity [22]. Floxuridine (FUDR) is the most widely used agent in internal pumps because of the short half-life and high first-pass metabolism rate allowing for increased concentration of the drug in hepatic tumors and lower concentrations systemically [21]. Newer chemotherapy drugs have also been used for intrahepatic therapy including irinotecan [23] and oxaliplatin [24, 25]. Chinese investigators using HAI CPT and oxaliplatin with bolus FUDR given only every $4-8$ weeks produced a $61 \%$ response rate and a median survival of 24.8 months in 31 patients [26]. Irinotecan is not as useful due to a lack of an extraction benefit [27].

\section{Toxicity of Hepatic Arterial Infusion Chemotherapy}

Systemic toxicities such as nausea, vomiting, mucositis, and myelosuppression are very low with HAI FUDR since the extraction rate with HAI of FUDR is 95\% [28, 29]. Extrahepatic profusion of FUDR into the gastrointestinal tract can cause diarrhea or gastric and duodenal ulcers [30]; however, the most common side effect of HAI FUDR therapy is biliary toxicity, being reflected in an elevation of liver enzymes or bilirubin [31]. Consequently, liver function tests should be monitored every 2 weeks during therapy and FUDR dose should be adjusted based on liver test results.

Dexamethasone can be combined with FUDR in the pump to decrease the risk of biliary toxicity [32]. In a randomized study, a decreased incidence of bilirubin elevation was seen in patients who received dexamethasone versus those who received FUDR alone (9 vs. $30 \%$, respectively; $\mathrm{p}=0.07$ ) [32]. Other methods used to prevent biliary toxicity include alternating HAI FUDR with HAI 5-fluorouracil (5-FU) [33, 34].

\section{Technical Aspects of Hepatic Arterial Infusion}

Regional HAI chemotherapy can be administered by a hepatic arterial port or pump. The catheter can be placed percutaneously and connected to an external pump, or connected through a surgically implanted pump. At the time of surgical pump placement, the distal gastroduodenal artery, the right gastric artery, and small collateral branches supplying the stomach, small bowel, and pancreas are ligated. The pump is placed in a subcutaneous pocket in the abdomen. A cholecystectomy is performed to prevent chemotherapy-induced cholecystitis. Blue dye is injected to ensure bilobar perfusion and to assess for extrahepatic perfusion [35]. Surgically implanted pumps enable long-term infusion with good patency of the catheter and hepatic artery as well as a low incidence of infection $[36,37]$.

\section{Hepatic Arterial Infusion in the Metastatic Setting}

Early studies using HAI FUDR without systemic chemotherapy demonstrated increased objective response rates compared to systemic chemotherapy with intravenous FUDR or 5-FU alone (41 vs. $14 \%$, respectively; $\mathrm{p}<0.01$ ), but did not show an increase in overall survival [38]. Using HAI 5-FU alone (not FUDR), response rates are somewhat lower (24\%) and survival is 19.2 months [39]. In a randomized study comparing HAI plus systemic bolus 5-FU/leucovorin (LV) $(\mathrm{n}=40)$ or HAI alone $(\mathrm{n}=36)$, there was an increase in survival in the combined group ( 20 vs. 14 months, $\mathrm{p}=0.0033$ ), but no significant increase in response rate [40]. More recently, newer systemic agents such as irinotecan and oxaliplatin have been evaluated with HAI. A study using HAI FUDR plus systemic irinotecan in previously treated patients produced a response rate of $74 \%$ and a median survival of 21 months [41]. Another study using HAI with systemic oxaliplatin combined with irinotecan or 5-FU/ LV (FOLFOX) demonstrated further improvement. Of those who received HAI FUDR plus oxaliplatin and CPT, 19 out of 21 (90\%) had a partial response and median survival was 35.8 months [42]. In a Chinese study in which half of the patients had extrahepatic disease, HAI FUDR plus systemic mFOLFOX6 produced a response rate of $68.6 \%$ and a median survival of 25 months [43].

In patients who are KRAS wild-type, systemic chemotherapy agents which target the epidermal growth factor, such as cetuximab and panitumumab, can be used. In new studies in patients with KRAS wild-type tumors, the median survival has been reported to be as high as 30 months with modern systemic chemotherapy and cetuximab. In a review of 75 patients with unresectable liver metastases with known KRAS status treated with HAI and systemic chemotherapy, the median survival was 68 months for patients with KRAS wild-type tumors versus 29 months for patients with KRAS MUT (p < 0.003) (fig. 1) [44]. 


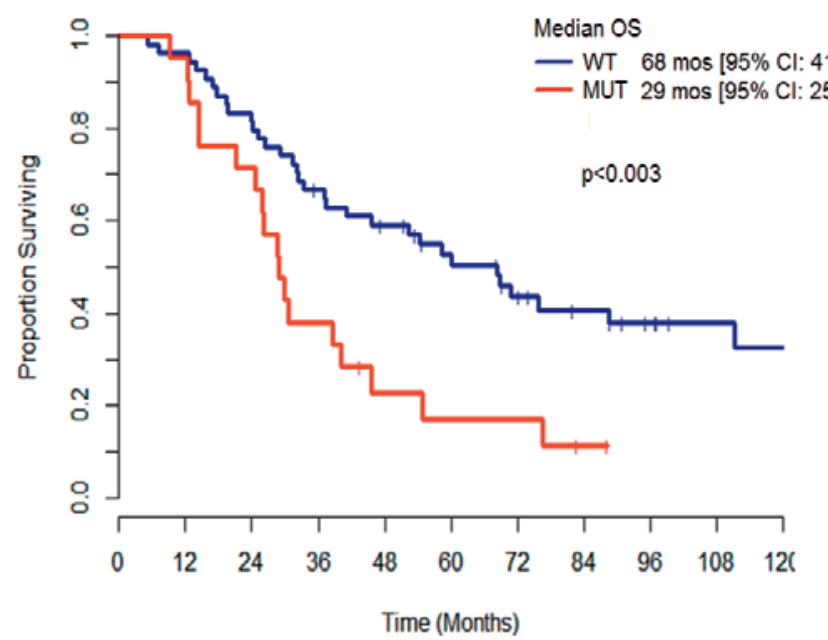

Fig. 1. Metastatic colorectal cancer: survival with hepatic arterial infusion and systemic chemotherapy.

\section{Hepatic Arterial Infusion Chemotherapy in the Refractory \\ Metastatic Setting}

For patients who fail first-line chemotherapy, modern systemic chemotherapy agents such as irinotecan alone [45], irinotecan and cetuximab [46], and FOLFOX [47] produce response rates ranging from $9-22 \%$ and a median survival of 14 months or less. In patients who fail first- and second-line chemotherapy, therapeutic options are very limited. Regorafenib and TAS102 in the refractory setting demonstrate response rates of 1 and $1.6 \%$, respectively, and a median survival of 6.4 and 7.1 months, respectively $[48,49]$. In a recent publication of a heavily pretreated population of patients who had progressed after 5-FU/LV, oxaliplatin, and irinotecan therapies, the response rate was $33 \%$, the median survival was 20 months, and the progression-free survival was 6 months after using HAI plus systemic therapy [50]. 19 of 57 (33\%) patients had a partial response and 31 (54\%) had stable disease.

\section{Role of Hepatic Arterial Infusion in the Metastatic Setting: \\ Converting Unresectable to Resectable Liver Disease}

In patients who are diagnosed with liver-only metastases not amenable to surgery, treatment with systemic chemotherapy can decrease tumor size and convert approximately $15-30 \%$ of inoperable patients to operable [51], especially when targeted chemotherapy agents are used [52]. In a study conducted at Memorial Sloan Kettering Cancer Center, 49 patients with unresectable (i.e. lesions involving at least six segments in combination with involvement of major vessels which would require resection of vessels to achieve an $\mathrm{R} 0$ resection) CRC liver metastases were treated with HAI FUDR/Dex plus systemic oxaliplatin and irinotecan [8]. 92\% of the 49 patients had a complete $(8 \%)$ or partial $(84 \%)$ response. $47 \%$ of patients were able to proceed with liver resection with curative intent. Figure 2 shows the volume of reduction in disease allowing patients to get to resection. In patients who were chemotherapynaïve, the median survival was 50.8 months, and for patients who were previously treated the median survival was 35 months.

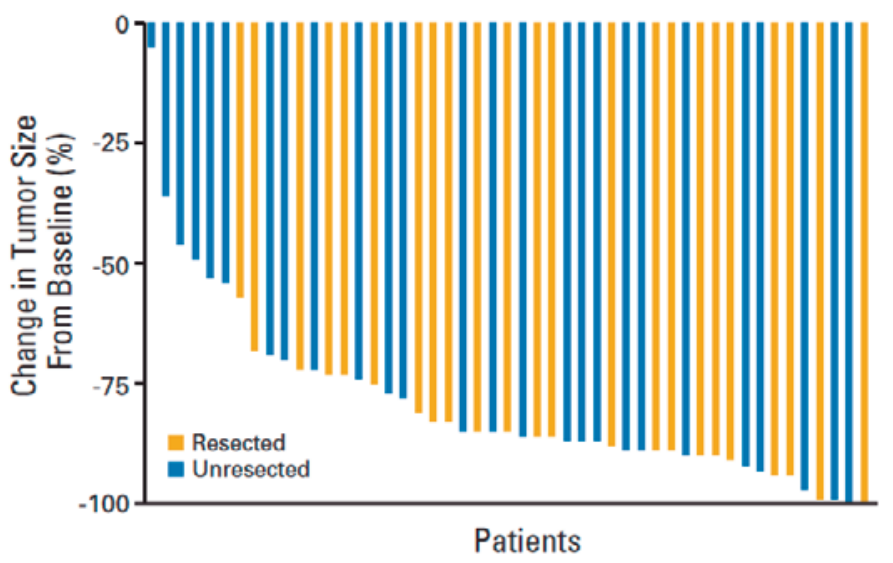

Fig. 2. Waterfall graph depicting the decrease in tumor measurements from baseline in patients treated with hepatic arterial infusion floxuridine/dexamethasone plus systemic oxaliplatin/irinotecan. -100 means $100 \%$ decrease in tumor. Blue bars represent patients who were not able to undergo resection. Gold bars represent patients who, though initially unresectable, after response with hepatic arterial infusion and systemic chemotherapy were able to undergo resection. Adapted from [8]. Reprinted with permission. ${ }^{\circledR} 2017$ American Society of Clinical Oncology. All rights reserved.

D'Angelica et al. [53] evaluated 49 patients with unresectable liver metastases from CRC treated with HAI plus systemic chemotherapy in a prospective study. The overall response rate was $76 \%$, $47 \%$ of patients were converted to resection at 6 months after treatment start, and median overall survival for all patients was 38 months. An updated analysis of this study with a median follow-up among survivors of 63 months reported a 52\% conversion to resection at a median of 5 months, an overall survival of 37.4 months, and 5-year survival of 36\% [54].

In 39 patients progressing on oxaliplatin therapy and then treated with HAI FUDR/Dex plus systemic irinotecan, the response rate was $44 \%$, with $18 \%$ of these patients undergoing surgical resection or ablation [55]. In patients treated with HAI oxaliplatin via a port and systemic 5-FU/LV, of which $75 \%$ were previously treated, $19 \%$ of patients were converted from unresectable to resectable [25]. Another study with 54 patients who were all previously treated with prior systemic FOLFIRI or FOLFOX, HAI oxaliplatin via an intrahepatic arterial catheter connected to a subcutaneous port and systemic 5-FU/LV resulted in 18\% conversion to resection [56].

\section{Hepatic Arterial Infusion as Adjuvant Therapy after Hepatic Resection}

HAI chemotherapy can be used in conjunction with surgery and systemic chemotherapy to target metastatic disease from CRC to the liver. Hepatic resection of colorectal liver metastases has improved 5 -year survival rates $[9,57]$. Nearly $70 \%$ of patients develop recurrent disease after hepatic resection, usually within 2 years, and $30-50 \%$ develop isolated hepatic metastases $[58,59]$. Adjuvant regional therapy with HAI can target residual micrometastatic disease in the liver, in conjunction with systemic therapy to reduce systemic recurrence. Several randomized studies have compared HAI plus systemic therapy versus systemic therapy alone. 
Fig. 3. Updated overall survival after adjuvant treatment with hepatic arterial infusion and systemic chemotherapy after liver resection. Adapted from [68]. Reprinted with permission. (c) 2017 John Wiley and Sons. All rights reserved.

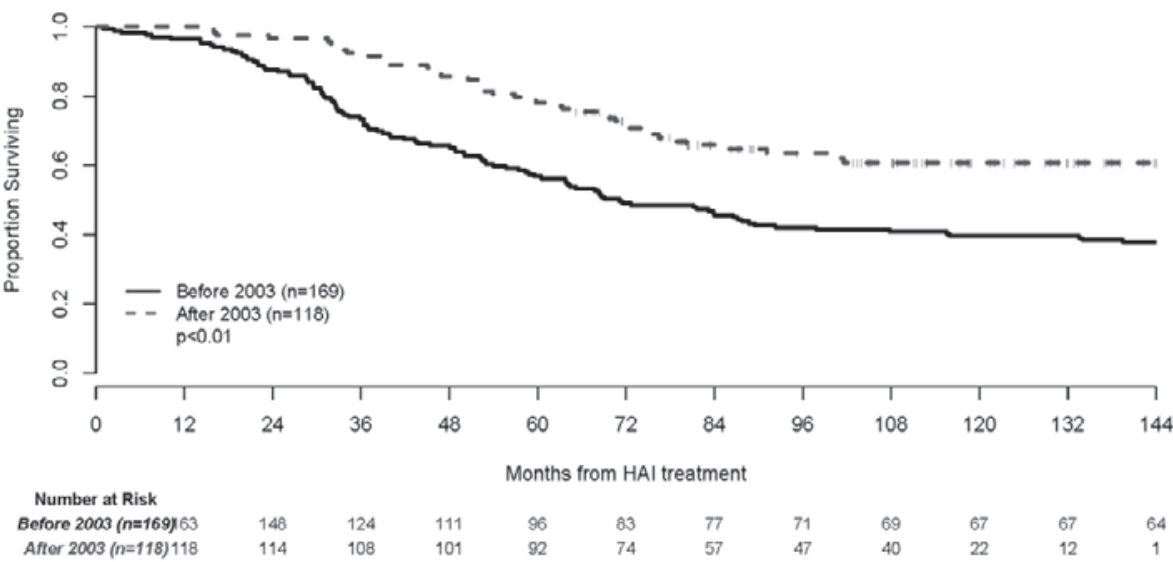

Table 1. Randomized studies after liver resection: hepatic disease-free survival

\begin{tabular}{|c|c|c|c|c|c|c|}
\hline \multirow[t]{2}{*}{ Studies } & \multirow[t]{2}{*}{$\mathrm{n}$} & \multicolumn{2}{|c|}{ 2-year, \% } & \multicolumn{2}{|c|}{ 5-year, \% } & \multirow[t]{2}{*}{$\mathrm{p}$ value } \\
\hline & & HAI & SYS & HAI & SYS & \\
\hline MSKCC & 156 & 90 & 60 & 75 & 40 & 0.0001 \\
\hline ECOG & 75 & 75 & 50 & 70 & $40^{\mathrm{a}}$ & 0.0001 \\
\hline Lorenz & 186 & \multicolumn{2}{|c|}{ median } & \multicolumn{2}{|c|}{$43 / 27^{\mathrm{a}}$} & NS \\
\hline Lygidakis & 122 & 90 & 60 & 85 & 50 & 0.0001 \\
\hline
\end{tabular}

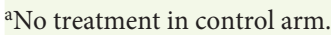

$\mathrm{HAI}=$ Hepatic arterial infusion; SYS = systemic therapy.

A randomized trial at Memorial Sloan Kettering Cancer Center compared 156 patients who were resected and then randomized to receive HAI FUDR/Dex combined with systemic intravenous 5-FU/LV $(\mathrm{n}=74)$ and 5-FU/LV alone $(\mathrm{n}=82)$ [60]. The endpoint was 2 -year survival which was significantly improved with HAI FUDR/Dex plus intravenous 5-FU/LV (86\%) versus 72\% for 5-FU/ LV alone $(\mathrm{p}=0.03)$. In addition, there was an excellent 2 -year hepatic disease-free survival (HDFS) (90 vs. 60\%, p < 0.001) for those who received HAI FUDR/Dex + intravenous 5-FU/LV versus systemic therapy alone. In 2005, updated results were published and showed a 10 -year survival rate of $41 \%$ in the group who received HAI FUDR/Dex plus intravenous 5-FU/LV compared to $27.2 \%$ in the group who received intravenous 5-FU/LV alone, as well as a longer overall progression-free survival (31.3 vs. 17.2 months, respectively; $\mathrm{p}=0.02$ ) [61].

A trial done by the Eastern Cooperative Oncology Group and the Southwestern Oncology Group randomized patients after hepatic resection to HAI FUDR and intravenous 5-FU versus surgery alone [62]. The endpoint was disease-free survival (DFS). For those receiving HAI FUDR and intravenous 5-FU/LV versus no further therapy, the 4 -year DFS was 46 versus $25 \%$, respectively $(\mathrm{p}=0.04$ ), and liver recurrence-free survival was 67 versus $43 \%$, respectively $(\mathrm{p}=0.03)$.

DFS and HDFS of four randomized studies show a significant increase in HDFS and overall DFS in three of four studies (table 1).

HAI has been combined with more modern systemic therapy. A phase I/II study evaluated patients who underwent liver resection followed by HAI FUDR/Dex plus systemic irinotecan [63]. There was a 2 -year survival of $89 \%$ and at 18 months HDFS was $88 \%$ and overall DFS was $47 \%$. Another phase I study evaluated HAI FUDR/ Dex plus systemic oxaliplatin and 5-FU/LV after liver resection [64]. The 3-year survival was $88 \%$; with a median follow-up of 43 months the median survival was not reached. At 3 years, hepatic progression-free survival was $86 \%$ and overall progression-free survival was $50 \%$. A North Central Cancer Treatment Group (NCCTG) phase II study looked at adjuvant HAI FUDR plus systemic 5-FU/LV in 49 patients who had resection of bilobar disease [65]. Their endpoint was a 2 -year survival of $85 \%$ which was reached.

Other retrospective studies have also shown that adjuvant HAI following liver resection prolongs hepatic progression-free survival and progression-free survival. A review by Ito et al. [66] on 1,021 patients showed that HAI therapy after liver resection was associated with improved overall survival in a multivariate analysis. Can similar results be obtained with modern systemic therapy alone? House et al. [67] looked at patients who were resected between 2001 and 2005 and matched 125 patients treated with modern therapy (FOLFOX or FOLFIRI) with 125 patients who received HAI plus systemic chemotherapy. With a median follow-up of 43 months, patients treated with HAI FUDR plus systemic chemotherapy had a higher 5-year survival compared to patients treated with systemic chemotherapy alone, i.e. 72 versus $52 \%$, respectively $(p=0.004)$. The 5-year hepatic recurrence-free survival was also improved for patients treated with HAI plus systemic therapy versus those treated with systemic therapy alone, i.e. 79 versus $55 \%$, respectively ( $\mathrm{p}<0.001)$.

A pooled analysis of patients enrolled into four consecutive prospective adjuvant protocols using HAI and systemic chemotherapy after liver resection was done at Memorial Sloan Kettering Cancer Center [68]. The analysis included 287 patients who were enrolled in trials from October 1991 to September 2009. Patients were divided into two groups: those treated before and those after 2003. The median follow-up for patients enrolled before 2003 was 15 years. In that group the systemic chemotherapy consisted of 5-FU/ LV or irinotecan added to HAI. The 5-year survival was 56\% (95\% confidence interval (CI): 49-64\%) and the 10-year survival was $40 \%$ (95\% CI: 32-47\%) with a median survival of 71 months 
(fig. 3). For patients enrolled after 2003, the median follow-up was 9 years and the median survival has not been reached. Systemic chemotherapy consisted of FOLFOX, FOLFIRI \pm bevacizumab. The 5-year survival was 78\% (95\% CI: 70-84\%) and the 10 -year survival was $61 \%$ (95\% CI: $51-70 \%$ ) (fig. 3).

The use of HAI plus systemic chemotherapy in relation to a patient's KRAS mutational status has been reported. In 169 patients who underwent liver resection followed by adjuvant HAI FUDR and systemic chemotherapy, the 3-year overall survival was 95 versus $81 \%$ for KRAS wild-type $(\mathrm{n}=118)$ and KRAS mutated $(\mathrm{n}=51)$ patients, respectively [69].

\section{Conclusion}

CRC is a major public health problem, and even with increased efforts of screening patients are still diagnosed with stage IV disease. Approximately $25 \%$ of patients will have metastatic liver disease at diagnosis. Some of these patients are potentially curable with a combination of liver therapies including liver surgery, ablation, and HAI therapy. Evaluation of patients with oligometastatic disease to the liver for liver therapies including HAI therapy should be routinely considered. In patients with unresectable metastases to the liver, HAI can be used with systemic chemotherapy to achieve increased response rates even in patients after progression on first- and second-line chemotherapy. Results show an increased response and conversion to resection with the use of HAI and systemic therapy versus systemic therapy alone. For patients who have unresectable liver disease, the use of HAI plus systemic chemotherapy can convert patients to resection and allow patients to have a chance for cure. In patients who have resectable liver disease, HAI therapy given with systemic chemotherapy after resection can increase DFS and HDFS. Three of four randomized trials comparing HAI and systemic chemotherapy versus systemic chemotherapy alone or control showed a significant increase in DFS and HDFS. HAI can be administered via a surgically implanted pump, hepatic arterial port, or percutaneously placed catheter connected to an external pump. Systemic toxicities are very low with HAI due to a high first-pass extraction rate, allowing combination with systemic therapies. Hepatic toxicities have to be carefully monitored. In summary, HAI with systemic chemotherapy is a reasonable treatment option in select patients with oligometastatic disease to the liver in order to achieve improved outcomes.

\section{Disclosure Statement}

Dr. Nancy Kemeny receives funding from Amgen for research. There are no additional conflicts of interest.

\section{References}

1 Ferlay J, Soerjomataram I, Ervik M, Dikshit R, Eser S Mathers C, Rebelo M, Parkin DM, Forman D, Bray F: GLOBOCAN 2012 v1.0. Cancer Incidence and Mortality Worldwide: IARC CancerBase No. 11. http://globocan.iarc.fr (accessed October 20, 2016).

2 American Cancer Society: Key Statistics for Colorectal Cancer (2016). www.cancer.org/cancer/colonandrectumcancer/detailedguide/colorectal-cancer-key-statistics.

3 Siegel R, Naishadham D, Jemal A: Cancer statistics, 2012. CA Cancer J Clin 2012;62:10-29.

4 Scheele J, Stangle R, Altendorf-Hofmann A: Hepatic metastases from colorectal carcinoma: impact of surgical resection on the natural history. Br J Surg 1990;77: 1241-1246.

5 Sanoff HK, Sargent DJ, Campbell ME, Morton RF, Fuchs CS, Ramanathan RK, Williamson SK, Findlay BP, Pitot HC, Goldberg RM: Five-year data and prognostic factor analysis of oxaliplatin and irinotecan combinations for advanced colorectal cancer: N9741. J Clin Oncol 2008;26:5721-5727.

6 Bismuth H, Adam R, Lévi F, Farabos C, Waechter F, Castaing D, Majno P, Engerran L: Resection of nonresectable liver metastases from colorectal cancer after neoadjuvant chemotherapy. Ann Surg 1996;224:509520; discussion 520-522.

7 Adam R, Avisar E, Ariche A, Giachetti S, Azoulay D Castaing D, Kunstlinger F, Levi F, Bismuth F: Fiveyear survival following hepatic resection after neoadjuvant therapy for nonresectable colorectal. Ann Surg Oncol 2001;8:347-353.
8 Kemeny NE, Melendez FD, Capanu M, Paty PB, Fong Y, Schwartz LH, Jarnagin WR, Patel D, D’Angelica M: Conversion to resectability using hepatic artery infusion plus systemic chemotherapy for the treatment of unresectable liver metastases from colorectal carcinoma. J Clin Oncol 2009;27:3465-3471.

9 Fong Y, Fortner J, Sun RL, Brennan MF, Blumgart LH: Clinical score for predicting recurrence after hepatic resection for metastatic colorectal cancer: analysis of 1001 consecutive cases. Ann Surg 1999;230:309-318; discussion 318-321.

10 Kopetz S, Chang GJ, Overman MJ, Eng C, Sargent DJ, Larson DW, Grothey A, Vauthey JN, Nagorney DM, McWilliams RR: Improved survival in metastatic colorectal cancer is associated with adoption of hepatic resection and improved chemotherapy. J Clin Oncol 2009;27:3677-3683.

11 de Gramont A, Figer A, Seymour M, Homerin M, Hmissi A, Cassidy J, Boni C, Cortes-Funes H, Cervantes A, Freyer G, Papamichael D, Le Bail N, Louvet C, Hendler D, de Braud F, Wilson C, Morvan F, Bonetti A: Leucovorin and fluorouracil with or without oxaliplatin as first-line treatment in advanced colorectal cancer. J Clin Oncol 2000;18:2938-2947.

12 Saltz LB, Cox JV, Blanke C, Rosen LS, Fehrenbacher L, Moore MJ, Maroun JA, Ackland SP, Locker PK, Pirotta N, Elfring GL, Miller LL: Irinotecan plus fluorouracil and leucovorin for metastatic colorectal cancer. Irinotecan Study Group. N Engl J Med 2000;343: 905-914.
13 Tournigand C, André T, Achille E, Lledo G, Flesh M, Mery-Mignard D, Quinaux E, Couteau C, Buyse M, Ganem G, Landi B, Colin P, Louvet C, de Gramont A: FOLFIRI followed by FOLFOX6 or the reverse sequence in advanced colorectal cancer: a randomized GERCOR study. J Clin Oncol 2004;22:229-237.

14 Hurwitz HI, Fehrenbacher L, Hainsworth JD, Heim W, Berlin J, Holmgren E, Hambleton J, Novotny WF, Kabbinavar F: Bevacizumab in combination with fluorouracil and leucovorin: an active regimen for first-line metastatic colorectal cancer. J Clin Oncol 2005;23: 3502-3508.

15 Cunningham D, Humblet Y, Siena S, Khayat D, Bleiberg H, Santoro A, Bets D, Mueser M, Harstrick A, Verslype C, Chau I, Van Cutsem E: Cetuximab monotherapy and cetuximab plus irinotecan in irinotecanrefractory metastatic colorectal cancer. $\mathrm{N}$ Engl J Med 2004;351:337-345.

16 Amado RG, Wolf M, Peeters M, Van Cutsem E, Siena S, Freeman DJ, Juan T, Sikorski R, Suggs S, Radinsky R, Patterson SD, Chang DD: Wild-type KRAS is required for panitumumab efficacy in patients with metastatic colorectal cancer. J Clin Oncol 2008;26:16261634.

17 Frankel TL, D’Angelica MI: Hepatic resection for colorectal metastases. J Surg Oncol 2014;109:2-7.

18 Andres A, Majno PE, Morel P, Rubbia-Brandt L, Giostra E, Gervaz P, Terraz S, Allal AS, Roth AD, Mentha G: Improved long-term outcome of surgery for advanced colorectal liver metastases: reasons and implications for management on the basis of a severity score. Ann Surg Oncol 2008; 15:134-143. 
19 Sofocleous CT, Violari EG, Sotirchos VS, Shady W, Gonen M, Pandit-Taskar N, Petre EN, Brody LA, Alago W, Do RK, D’Angelica MI, Osborne JR, Segal NH, Carrasquillo JA, Kemeny NE: Radioembolization as a salvage therapy for heavily pretreated patients With colorectal cancer liver metastases: factors that affect outcomes. Clin Colorectal Cancer 2015;14:296-305.

20 Breedis C, Young G: The blood supply of neoplasms in the liver. Am J Pathol 1954;30:969-977.

21 Ensminger WD, Gyves JW: Clinical pharmacology of hepatic arterial chemotherapy. Semin Oncol 1983;10: 176-182.

22 Melendez FDH, Kemeny N: Clinical management of patients with colorectal liver metastasis using hepatic arterial infusion; in Geschwind J-FH, Soulen MC (eds): Interventional Oncology: Principles and Practice. New York, NY, Cambridge University Press, 2008, pp 249263.

23 van Riel JM, van Groeningen CJ, Kedde MA, Gall H, Leisink JM, Gruia G, Pinedo HM, van der Vijgh WJ, Giaccone G: Continuous administration of irinotecan by hepatic arterial infusion: a phase I and pharmacokinetic study. Clin Cancer Res 2002;8:405-412.

24 Dzodic R, Gomez-Abuin G, Rougier P, Bonnay M, Ardouin P, Gouyette A, Rixe O, Ducreux M, Munck JN: Pharmacokinetic advantage of intra-arterial hepatic oxaliplatin administration: comparative results with cisplatin using a rabbit VX2 tumor model. Anticancer Drugs 2004;15:647-650

25 Ducreux M, Ychou M, Laplanche A, Gamelin E, Lasser P, Husseini F, Quenet F, Viret F, Jacob JH, Boige V, Elias D, Delperro JR, Luboinski M; gastrointestinal group of the Federation Nationale des Centres de Lutte Contre le Cancer: Hepatic arterial oxaliplatin infusion plus intravenous chemotherapy in colorectal cancer with inoperable hepatic metastases: a trial of the gastrointestinal group of the Federation Nationale des Centres de Lutte Contre le Cancer. J Clin Oncol 2005; 23:4881-4887.

26 Chen Y, Wang X, Yan Z, Wang J, Luo J, Liu Q: Hepatic arterial infusion with irinotecan, oxaliplatin, and floxuridine plus systemic chemotherapy as first-line treatment of unresectable liver metastases from colorectal cancer. Onkologie 2012;35:480-484.

27 van Riel JM, van Groeningen CJ, de Greve J, Gruia G, Pinedo HM, Giaccone G: Continuous infusion of hepatic arterial irinotecan in pretreated patients with colorectal cancer metastatic to the liver. Ann Oncol 2004; 15:59-63.

28 Ensminger WD, Rosowsky A, Raso V, Levin DC, Glode M, Come S, Steele G, Frei E: A clinical-pharmacological evaluation of hepatic arterial infusions of 5-fluoro-2'-deoxyuridine and 5-fluorouracil. Cancer Res 1978;38:3784-3792.

29 Collins JM: Pharmacologic rationale for regional drug delivery. J Clin Oncol 1984;2:498-504.

30 Gluck WL, Akwari OE, Kelvin FM, Goodwin BJ: A reversible enteropathy complicating continuous hepatic artery infusion chemotherapy with 5-fluoro-2-deoxyuridine. Cancer 1985;56:2424-2427.

31 Cohen AD, Kemeny NE: An update on hepatic arterial infusion chemotherapy for colorectal cancer. Oncologist 2003;8:553-566.

32 Kemeny N, Seiter K, Niedzwiecki D, Chapman D, Sigurdson E, Cohen A, Botet J, Oderman P, Murray P: A randomized trial of intrahepatic infusion of fluorodeoxyuridine with dexamethasone versus fluorodeoxyuridine alone in the treatment of metastatic colorectal cancer. Cancer 1992;69:327-334.
33 Stagg RJ, Venook AP, Chase JL, Lewis BJ, Warren RS, Roh M, Mulvihill SJ, Grobman BJ, Rayner AA, Hohn DC: Alternating hepatic intra-arterial floxuridine and fluorouracil: a less toxic regimen for treatment of liver metastases from colorectal cancer. J Natl Cancer Inst 1991;83:423-428.

34 Davidson BS, Izzo F, Chase JL, DuBrow RA, Patt Y, Hohn DC, Curley SA: Alternating floxuridine and 5-fluorouracil hepatic arterial chemotherapy for colorectal liver metastases minimizes biliary toxicity. Am J Surg 1996;172:244-247.

35 Ammori JB, Kemeny NE: Regional hepatic chemotherapies in treatment of colorectal cancer metastases to the liver. Semin Oncol 2010;37:139-148.

36 Ensminger W, Niederhuber J, Dakhil S, Thrall J, Wheeler R: Totally implanted drug delivery system for hepatic arterial chemotherapy. Cancer Treat Rep 1981; 65:393-400.

37 Kemeny N, Fong Y: Treatment of liver metastases; in Holland JF, Frei E, Bast RC Jr, Kufe DW, Morton DL, Weichselbaum RR (eds): Cancer Medicine, ed 4. Baltimore, Williams \& Wilkins, 1997, pp 1939-1953.

38 Meta-Analysis Group in Cancer; Piedbois P, Buyse M, Kemeny N, Rougier P, Carlson R, Allen-Mersh T, O'Connell M, Chang A, Sondak V, Kemeny M, Levy E: Reappraisal of hepatic arterial infusion in the treatment of nonresectable liver metastases from colorectal cancer. J Natl Cancer Inst 1996;88:252-258.

39 Arai Y, Aoyama A, Inaba Y, Okabe H, Ihaya T, Kichikawa K, Ohashi Y, Sakamoto J, Oba K, Saji S: Phase II study on hepatic arterial infusion chemotherapy using percutaneous catheter placement techniques for liver metastases from colorectal cancer (JFMC28 study). Asia Pac J Clin Oncol 2015;11:41-48.

40 Fiorentini G, Cantore M, Rossi S, Vaira M, Tumolo S, Dentico P, Mambrini A, Bernardeschi P, Turrisi G, Giovanis P, Guadagni S, Valori V, De Simone M: Hepatic arterial chemotherapy in combination with systemic chemotherapy compared with hepatic arterial chemotherapy alone for liver metastases from colorectal cancer: results of a multi-centric randomized study. In Vivo 2006;20:707-709.

41 Kemeny N, Gonen M, Sullivan D, Schwartz L, Benedetti F, Saltz L, Stockman J, Fong Y, Jarnagin W, Bertino J, Tong W, Paty P: Phase I study of hepatic arterial infusion of floxuridine and dexamethasone with systemic irinotecan for unresectable hepatic metastases from colorectal cancer. J Clin Oncol 2001;19:2687-2695.

42 Kemeny N, Jarnagin W, Paty P, Gönen M, Schwartz L, Morse M, Leonard G, D'Angelica M, DeMatteo R, Blumgart L, Fong Y: Phase I trial of systemic oxaliplatin combination chemotherapy with hepatic arterial infusion in patients with unresectable liver metastases from colorectal cancer. J Clin Oncol 2005;23:48884896.

43 Li C, Gu Y, Zhao M, Yuan Y, Wang F, Wang Z, Li W, Luo H, Chen C, Chen G, Ding P, Wu X, Lu Z, Pan Z, Xu R, He Y, Wan D, Li Y: Phase I trial of hepatic arterial infusion (HAI) of floxuridine with modified oxaliplatin, 5-fluorouracil and leucovorin (m-FOLFOX6) in Chinese patients with unresectable liver metastases from colorectal cancer. Cancer Chemother Pharmacol 2014;74:1079-1087.

44 Connell L, Chou JF, Boucher TM, Capanu M, Kemeny NE: Relevance of CEA and LDH in relation to KRAS status in patients with unresectable colorectal liver metastases. J Clin Oncol 2016;34(suppl 4):abstr 762.

45 Rothenberg ML, Eckardt JR, Kuhn JG, Burris HA 3rd, Nelson J, Hilsenbeck SG, Rodriguez GI, Thurman AM, Smith LS, Eckhardt SG, Weiss GR, Elfring GL, Rinaldi DA, Schaaf LJ, Von Hoff DD: Phase II trial of irinotecan in patients with progressive or rapidly recurrent colorectal cancer. J Clin Oncol 1996;14:1128-1135.
46 Cunningham D, Humblet Y, Siena S, Khayat D, Bleiberg H, Santoro A, Bets D, Mueser M, Harstrick A, Verslype C, Chau I, Van CE: Cetuximab monotherapy and cetuximab plus irinotecan in irinotecan-refractory metastatic colorectal cancer. N Engl J Med 2004;351: 337-345.

47 Rothenberg ML, Oza AM, Bigelow RH, Berlin JD, Marshall JL, Ramanathan RK, Hart LL, Gupta S, Garay CA, Burger BG, Le BN, Haller DG: Superiority of oxaliplatin and fluorouracil-leucovorin compared with either therapy alone in patients with progressive colorectal cancer after irinotecan and fluorouracil-leucovorin: interim results of a phase III trial. J Clin Oncol 2003;21:2059-2069.

48 Grothey A, Van Cutsem E, Sobrero A, Siena S, Falcone A, Ychou M, Humblet Y, Bouché O, Mineur L, Barone C, Adenis A, Tabernero J, Yoshino T, Lenz HJ, Goldberg RM, Sargent DJ, Cihon F, Cupit L, Wagner A, Laurent D; CORRECT Study Group: Regorafenib monotherapy for previously treated metastatic colorectal cancer (CORRECT): an international, multicentre, randomised, placebo-controlled, phase 3 trial. Lancet 2013;381:303-312.

49 Mayer RJ, Van Cutsem E, Falcone A, et al.; RECOURSE Study Group. Randomized trial of TAS-102 for refractory metastatic colorectal cancer. N Engl J Med 2015;372:1909-1919.

50 Cercek A, Boucher TM, Gluskin J, Aguilo A, Chou JF, Connell LC, Capanu M, Reidy-Lagunes D, D'Angelica $\mathrm{M}$, Kemeny NE: Response rates of hepatic arterial infusion pump therapy in patients with metastatic colorectal cancer liver metastases refractory to all standard therapies. J Surg Oncol 2016;114:655-663.

51 Barone C, Nuzzo G, Cassano A, Basso M, Schinzari G, Giuliante F, D'Argento E, Trigila N, Astone A, Pozzo C: Final analysis of colorectal cancer patients treated with irinotecan and 5-fluorouracil plus folinic acid neoadjuvant chemotherapy for unresectable liver metastases. Br J Cancer 2007;97:1035-1039.

52 Tabernero J, Van Cutsem E, Díaz-Rubio E, Cervantes A, Humblet Y, André T, Van Laethem JL, Soulié P, Casado E, Verslype C, Valera JS, Tortora G, Ciardiello F, Kisker O, de Gramont A: Phase II trial of cetuximab in combination with fluorouracil, leucovorin, and oxaliplatin in the first-line treatment of metastatic colorectal cancer. J Clin Oncol 2007;25:5225-5232.

53 D'Angelica M, Correa-Gallego C, Paty P, Cercek A, Gewirtz A, Chou JF, Marinella Capanu M, Kingham TP, Fong Y, DeMatteo RP, Allen PJ, Jarnagin WR, Kemeny N: Phase II trial of hepatic artery infusional and systemic chemotherapy for patients with unresectable hepatic metastases from colorectal cancer: conversion to resection and long-term outcomes. Ann Surg 2015; 261:353-360.

54 Ma LW, Kemeny NE, Capanu M, Chou JF, Cercek A, Kingham TP, Allen PJ, DeMatteo RP, Jarnagin WR, D'Angelica MI: Prospective phase II trial of combination hepatic artery and systemic chemotherapy for unresectable colorectal liver metastases: long term results and curative potential. J Am Coll Surg 2016;223:S78S79.

55 Gallagher DJ, Raggio G, Capanu M, Kemeny N: Hepatic arterial infusion plus systemic irinotecan in patients with unresectable hepatic metastases from colorectal cancer previously treated with systemic oxaliplatin: a retrospective analysis. Ann Oncol 2007;18:19951999.

56 Boige V, Malka D, Elias D, Castaing M, De Baere T Goere D, Dromain C, Pocard M, Ducreux M: Hepatic arterial infusion of oxaliplatin and intravenous LV5FU2 in unresectable liver metastases from colorectal cancer after systemic chemotherapy failure. Ann Surg Oncol 2008;15:219-226. 
57 Rees M, Tekkis PP, Welsh FK, O’Rourke T, John TG: Evaluation of long-term survival after hepatic resection for metastatic colorectal cancer: a multifactorial model of 929 patients. Ann Surg 2008;247:125-135.

58 Muratore A, Polastri R, Bouzari H, Vergara V, Ferrero A, Capussotti L: Repeat hepatectomy for colorectal liver metastases: a worthwhile operation? J Surg Oncol 2001;76:127-132.

59 Topal B, Kaufman L, Aerts R, Penninckx F: Patterns of failure following curative resection of colorectal liver metastases. Eur J Surg Oncol 2003;29:248-253.

60 Kemeny N, Huang Y, Cohen AM, Shi W, Conti JA Brennan MF, Bertino JR, Turnbull AD, Sullivan D, Stockman J, Blumgart LH, Fong Y: Hepatic arterial infusion of chemotherapy after resection of hepatic metastases from colorectal cancer. N Engl J Med 1999; 341:2039-2048.

61 Kemeny NE, Gonen M: Hepatic arterial infusion after liver resection. N Engl J Med 2005;352:734-735.

62 Kemeny MM, Adak S, Gray B, Macdonald JS, Smith T, Lipsitz S, Sigurdson ER, O’Dwyer PJ, Benson AB 3rd: Combined-modality treatment for resectable metastatic colorectal carcinoma to the liver: surgical resection of hepatic metastases in combination with continuous infusion of chemotherapy - an intergroup study. J Clin Oncol 2002;20:1499-1505.
63 Kemeny N, Jarnagin W, Gonen M, Stockman J, Blumgart L, Sperber D, Hummer A, Fong Y: Phase I/II study of hepatic arterial therapy with floxuridine and dexamethasone in combination with intravenous irinotecan as adjuvant treatment after resection of hepatic metastases from colorectal cancer. J Clin Oncol 2003; 21:3303-3309.

64 Kemeny N, Capanu M, D’Angelica M, Jarnagin W, Haviland D, Dematteo R, Fong Y: Phase I trial of adjuvant hepatic arterial infusion (HAI) with floxuridine (FUDR) and dexamethasone plus systemic oxaliplatin, 5-fluorouracil and leucovorin in patients with resected liver metastases from colorectal cancer. Ann Oncol 2009;20:1236-1241.

65 Bolton JS, O’Connell MJ, Mahoney MR, Farr GH Jr, Fitch TR, Maples WJ, Nagorney DM, Rubin J, Fuloria J, Steen PD, Alberts SR: Hepatic arterial infusion and systemic chemotherapy after multiple metastasectomy in patients with colorectal carcinoma metastatic to the liver: a North Central Cancer Treatment Group (NCCTG) phase II study, 92-46-52. Clin Colorectal Cancer 2012;11:31-37.
66 Ito H, Are C, Gonen M, D'Angelica M, Dematteo RP, Kemeny NE, Fong Y, Blumgart LH, Jarnagin WR: Effect of postoperative morbidity on long-term survival after hepatic resection for metastatic colorectal cancer. Ann Surg 2008;247:994-1002.

67 House MG, Kemeny NE, Gönen M, Fong Y, Allen PJ, Paty PB, DeMatteo RP, Blumgart LH, Jarnagin WR, D’Angelica MI: Comparison of adjuvant systemic chemotherapy with or without hepatic arterial infusional chemotherapy after hepatic resection for metastatic colorectal cancer. Ann Surg 2011;254:851-856.

68 Kemeny NE, Chou JF, Boucher TM, Capanu M, DeMatteo RP, Jarnagin WR, Allen PJ, Fong YC, Cercek A, D'Angelica MI: Updated long-term survival for patients with metastatic colorectal cancer treated with liver resection followed by hepatic arterial infusion and systemic chemotherapy. J Surg Oncol 2016;113:477-484.

69 Kemeny NE, Chou JF, Capanu M, Gewirtz AN, Cercek A, Kingham TP, Jarnagin WR, Fong YC, DeMatteo RP, Allen PJ, Shia J, Ang C, Vakiani E, D'Angelica MI: KRAS mutation influences recurrence patterns in patients undergoing hepatic resection of colorectal metastases. Cancer 2014;120:3965-3971. 